REsumo
Este artigo visa a interrogar o
discurso sobre o "fracasso da po-
lítica educacional" como um sin-
toma associado aos discursos do
mestre, do capitalismo e da uni-
versidade, implicando a presen-
ça real do inconsciente nos laços
sociais instituidos por meio do
campo das politicas educacionais
na contemporaneidade. Tratar
o fracasso educacional como sin-
toma levou a um deslocamento
da pergunta habitual "Por que
as politicas educacionais fracas-
sam?", para sustentar a bipó-
tese de que o fracasso retrata o
acontecimento do sujeito na es-
trutura discursiva. O estudo
mostrou a importância de incluir
o sujeito do desejo no campo de
análise das politicas educacio-
nais.
Descritores: fracasso educa-
cional; politica educacional; psi-
canálise; teoria do discurso.
a

\section{FRACASSO NA \\ IMPLEMENTAÇÃO DE POLÍTICAS \\ EDUCACIONAIS: SINTOMA E EMERGÊNCIA DO SUJEITO}

Eric Ferdinando Kanai Passone

A partir da experiência adquirida com pesquisas relacionadas à avaliação e ao planejamento de políticas educacionais e sociais, percebemos que, apesar de muitas vezes existirem boas intenções políticas, recursos financeiros e humanos, capacidade institucional e técnica, a execução de uma política apresenta hiatos entre o que é formulado e o que é implementado, sendo que os efeitos alcançados são totalmente distintos dos objetivos e metas previamente almejados. Em consonância com isso, para muitos pesquisadores, especialistas e educadores, a despeito do que se tem fei-

Docente da Faculdade de Ciências Humanas da Universidade Metodista de Piracicaba e pesquisador associado do Núcleo de Estudos de Políticas Públicas da Universidade Estadual de Campinas (UNICAMP), Campinas, SP, Brasil. 
to até agora (capacitações pedagógicas, avaliações, incentivos ao magistério, planos, programas e projetos específicos), os impactos e repercussões na aprendizagem dos alunos são pouco satisfatórios.

O que acontece efetivamente? Para os que se engajam no campo educacional, tornou-se um dilema responder à pergunta, parafraseando Hanna Arendt (1992), "Por que Joãozinho não aprende?". Em termos de análise das políticas educacionais, o discurso da análise de implementação e da avaliação surge como promessa e ilusão de transformação dos sistemas educacionais e das práticas educativas envolvendo crianças e adolescentes.

O fato é que temos presenciado o aumento do discurso avaliativo sobre o produto educacional, cada vez mais associado ao crescimento das exigências do desempenho das políticas educacionais, em torno da padronização e uniformização do sistema e do produto educacional. A partir dessa visão quase hegemônica, consideramos a existência de um discurso manifesto e/ou latente, explícito e/ou implícito, sobre o "fracasso das políticas educacionais", especificamente quando se coteja os resultados com os objetivos planejados e mensurados. Nessa lógica, o critério de sucesso e fracasso de uma dada política está definido por metas e parâmetros de análise e avaliação de políticas, como os instrumentos de monitoramento e avaliação externa do "produto" do sistema educacional.

De outro modo, neste artigo visamos a abordar o dito fracasso da política educacional como um sintoma associado aos discursos do mestre, do capitalismo e da universidade, interrogando a presença real do inconsciente nos laços sociais instituídos por meio do campo das políticas educacionais na contemporaneidade.

Para tanto, tratamos de definir nosso problema como sintoma e analisar os principais elementos da implementação educacional à luz do ferramental psicanalítico dos discursos. A (im)possível posição-sujeito nos discursos foi apreendida a partir do deslocamento analítico e dedutivo dessas estruturas discursivas, culminando na formulação de três pares análogos de discursos: o discurso da política educacional, o discurso do capitalismo no campo da educação e o discurso cientifico-universitário da análise de política educacional (Passone, 2012).

Ao sustentarmos que o fracasso da política educacional pode ser lido enquanto um sintoma inerente aos laços sociais estabelecidos por esses discursos, retomamos a positividade do sintoma ao remeter a uma mensagem que carece de sentido, ou ser interpreta- 
da. Assim, intenta-se um deslocamento da pergunta habitual "Por que as políticas educacionais fracassam?”, para afirmar e sustentar uma posição na qual o fracasso retrata o acontecimento do sujeito na estrutura. Em outras palavras, ali onde é dito fracasso educacional, está também o sujeito do desejo, enquanto desejo do desejo do Outro, bem como aponta para a possibilidade de uma prática educativa que precipite uma ruptura e a emergência da singularidade do sujeito em formação.

Os discursos oferecem suporte aos laços sociais, que, segundo Lacan, revestem as três atividades ou profissões consideradas por Freud impossíveis - ou seja, tais discursos se referem a impossibilidades que marcam os atos de governar, educar e curar, em sua totalidade. Tratar o dito fracasso enquanto um sintoma, que frustra os objetivos da civilização, implicou a inclusão da ordem do inconsciente nas relações sociais, pois não se trata de pensar a política somente na sua dimensão institucional ou sob aspectos da normatividade, mas de introduzir uma dimensão pulsional à análise de política. Isto é, ele significa o encontro ou a intersecção do desejo individual com o Outro da cultura, como sujeito dividido entre o desejo do outro e seu próprio desejo, enquanto pura diferença.

Essa via possibilitou-nos trabalhar, por um lado, com a dimensão do real, como impossibilidade de um saber todo, completo e absoluto, e, por outro, significou introduzir a questão do desejo, que remete sempre à falta-a-ser do sujeito. Será justamente o acontecimento do sujeito, esse efêmero simbólico real, que será esmaecido com o discurso científicouniversitário da análise de política. Como exemplo, temos o conhecimento produzido pelos discursos especializados de implementação e avaliação de políticas públicas, no qual o sujeito é reduzido a objeto de pesquisa, como resultado e desempenho da política. Assim, a produção do fracasso pôde ser pensada enquanto efeito discursivo, que se funda a partir do campo de análise e implementação educacional.

\section{Os discursos sobre a análise e implementação de políticas educacionais}

No campo dos discursos sobre a política educacional, as avaliações de resultados dos sistemas e programas educacionais constituem-se em uma das dimensões de pesquisa que envolvem a análise de políticas públicas, a qual tem sido aferida por meio de indicadores de desempenho e de monitoramento, que englobam avaliações de rendimento do sistema escolar e desempenho do aluno. Quando se tenta determinar quais questões incidem sobre o problema do fracasso das políticas educacionais, obser- 
vam-se pesquisas de diversos matizes teóricos e metodológicos que procuram compreender um conjunto de fatores e/ou causas determinantes, interno e/ou externo ao processo educacional, associado ao fracasso, tais como a escola, a relação professor/aluno, os recursos institucionais, os fatores psicológicos, cognitivos e afetivos do aluno, a saúde deste, os sistemas de ensino, a política (policy), o financiamento, os programas e os projetos pedagógicos e educacionais, a gestão da escola, a avaliação externa, a família e seu entorno social, os hábitos cotidianos dos alunos, os aspectos socioeconômicos, os capitais culturais e sociais etc.

Como sabemos, a política educacional representa um investimento considerável para os Estados sociais modernos, setor que detém um orçamento volumoso, quase sempre alvo de disputas dentro da arena política, suscitando questões sobre sua efetividade, eficácia e eficiência. Atualmente, os sistemas educacionais são responsabilizados por apresentarem melhores resultados de suas políticas, como apontamos, mensuráveis a partir dos indicadores, nacionais e internacionais, aplicados à educação. Tal realidade, como assinalado pelos especialistas, tem representado mudanças e o aumento de interesse na prática e na pesquisa de implementação de políticas educacionais, sustentando toda uma cadeia de produção de conhecimentos originários de diversas áreas ou disciplinas, tais como a economia, a sociologia, a psicologia, a administração e a pedagogia.

Ao percorrer esse campo, escolhi um foco específico como ponto de partida, o discurso do domínio e da eficiência: tudo saber, tudo controlar, tudo resolver e tudo poder esse discurso que, pode-se dizer, fomenta uma noção específica de "qualidade", "eficácia" e "avaliação" das políticas educacionais, que, por sua vez, são emblematicamente utilizadas por políticos, gestores, implementadores, meios de comunicação, estudiosos, organizações empresariais, agências de pesquisas etc. Assim, partimos da noção tradicional do fracasso da política, pensada como a diferença entre o que é almejado e esperado com a implementação da policy e os resultados objetivamente produzidos, em que a ideia de fracasso da política passou a estar associada aos diagnósticos, avaliações e monitoramento de resultados do sistema educacional.

Há, em quase todo discurso da análise de políticas educacionais, em toda pesquisa de avaliação, a seguinte pergunta: "A política ou programa social sob observação foi um sucesso ou um fracasso?" Para respondê-la, as análises de políticas educacionais utilizam os procedimentos de avaliação da política. Nesse caso, podemos constatar que as avaliações sobre a eficácia educacional estão diretamente relacionadas à produção do discurso sobre o fracasso, na medida em que nessa dimensão se visa, fundamental- 
mente, analisar se o programa "está sendo (ou foi) implementado de acordo com as diretrizes concebidas para a sua execução e se o seu produto atingirá (ou atingiu) as metas desejadas" (Figueiredo \& Figueiredo, 1986, p. 111).

Como ilustração, as publicações de instituições internacionais, como os boletins sobre a educação na América Latina, sinalizam que os países da região estão "ficando para trás" com relação aos demais continentes do mundo. Na última década, o Brasil foi reconhecido por seu aumento na "quantidade, sem qualidade" educacional (Preal, 2001). As políticas educacionais são hoje tema explícito da agenda política brasileira em todos os seus níveis de governo e um objeto sociomidiático, recorrentemente problematizado na opinião pública (Senne, 2009).

Nesse campo de análise da política educacional, os discursos sobre a implementação e a avaliação determinam a produção de uma noção específica de fracasso, relacionada aos resultados esperados (idealizados) e os efetivamente obtidos pela política educacional, em termos de produto educacional. Desse modo, as práticas e pesquisas sobre análises de políticas, implementação e avaliação passam a ser lidas enquanto discursos do domínio, na tentativa de responder ao que surge como fracasso, ilustrando o esforço simbólico de tais discursos de dominar o real, como função de verdade produzida pelos discursos de domínio sobre a realidade de tais práticas sociais.

\section{Uma abordagem do fracasso pelo discurso psicanalítico}

Um ano após os movimentos sociais de 1968, Lacan apresentou, em seu seminário 17, O avesso da psicanálise (1992), a noção de discurso como laço social, formulando o que ele denominou pelo neologismo "quadrípode" ou seus "quatro improvisos". Os discursos foram retratados por quatro fórmulas que representam as estruturas dos laços sociais básicos, as relações do sujeito com o outro, a função do objeto causa de desejo - objeto $a$, bem como a posição em que o sujeito se situa em relação à verdade de seu próprio ser, de seu próprio gozo e de seu saber, ou, mesmo, em relação 
aos ideais e fantasias que o orientam a partir de sua injunção simbólica com o real, promovido pelo laço social ou discurso.

A noção de discurso como laço social implicou deslocarmos a análise de conteúdo e significado comumente utilizada na análise de políticas públicas para compreendê-lo enquanto aparelhamento do gozo pela linguagem, ou seja, ela remete sempre ao poder de dominação do significante, que opera sobre a renúncia pulsional e instaura o sujeito do desejo. Seguindo essa linha de trabalho, o discurso compreende os efeitos inconscientes da linguagem, sendo que ele também funda e define a realidade psíquica e social da comunicação para o sujeito. O discurso é, portanto, um recurso específico da linguagem que fixa, cristaliza, a própria linguagem e usa seus recursos para estabelecer os laços sociais entre os seres falantes.

A articulação do sujeito com o discurso implica as relações que são produzidas e indica a dominância do laço social, ou seja, pelo tratamento que o outro recebe: todo laço social que trata o outro como escravo, ou um saber-produzir, insere-se no discurso do mestre; todo discurso que trata o outro como objeto retrata o discurso universitário; e todo laço social que trata o outro como consumidor e objeto de consumo inscreve-se na lógica do mestre moderno, o capitalismo. O discurso analítico é o único que trata o outro como sujeito.

A partir do discurso do mestre, que é, por excelência, o discurso do poder, associei o discurso da política educacional com a questão dos governos democráticos. Quanto ao discurso capitalista, propus pensá-lo no campo educacional, elegendo os seguintes elementos operacionais de análise: capital, capital humano, ciência e política educacional. Como desdobramento histórico dos discursos, também associei o discurso universitário-científico de análise da política educacional ao discurso da universidade.

Consideremos nosso primeiro discurso. A partir do discurso do mestre e dos elementos postulados no campo da análise de políticas, tais como policy, governo, implementadores e resultados, propusemos deduzir o que se produz por meio do discurso das políticas educacionais: o saber-fazer dos implementadores e o lugar residual que ocupa a criança e/ou o adolescente como objeto das políticas educacionais, reduzido a produto ou resultado da política. 

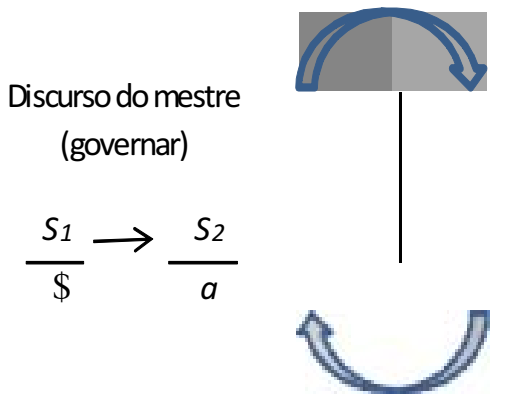

\section{Discurso da política educacional \\ (governar)}

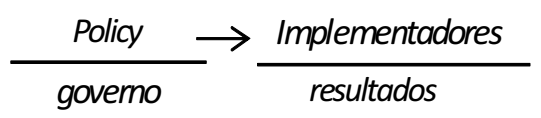

A política educacional surge como simbólico, dimensão material da policy, fruto do ciclo da política que ordena a realidade daqueles que trabalham na sua implementação. Isso se aplica tanto em relação ao domínio que ela exerce sobre seus agentes implementadores, os funcionários dessa agência, quanto em relação à dominação sobre seu público-alvo, os alunos, pois a articulação se faz na medida em que esse laço social ordena o outro a produzir, a fazer, a aprender, sendo que a dominância que a policy ocupa, enquanto simbólico, está estruturalmente marcada pelo real no que se refere aos resultados da política educacional - portanto, impossível.

Como agente (à esquerda e acima), a política (S1) está sustentada pela verdade (à esquerda e abaixo) dos governos, revelando que há um sujeito $(\$)$ em todo ato de governar. Os implementadores ocupam o lugar do outro (à direita e acima) no lugar do saber produzir (S2) - os profissionais da educação que trabalham com a coisa educacional. É justamente sob este lugar, que se produz sobre a perda do mais-de-gozar (objeto a) no ato de implementação, que o estudante ou aluno ocupa, como objeto $a$ (à direita e abaixo), o lugar da perda, no qual ele se apaga como sujeito, para produzir os resultados dessa política. Ao assumir tal posição, como dejeto da operação de gozo, enquanto pura perda, a criança fica presa no lugar de um produto, servindo de sustentação para o grande Outro, o Estado, o educador, a burocracia, a sociedade, a família etc.

Se esse laço social está marcado pelo domínio, a sua inscrição no discurso universitário transformará o aluno e os implementadores em objeto para sustentar sua prática de saber, como logo veremos com a escritura do discurso universitário-científico. A 
partir dessa variante do discurso, escrevemos o discurso capitalista no campo educacional. O capital passa a ser o significante-mestre, que domina todas as esferas da vida, controlando tudo, sendo o agente o sujeito dividido, que surge como capital humano, como sujeito do discurso capitalista, por fazer produzir e consumir. Conforme a estrutura abaixo, vemos que o capital passou a ocupar o poder do mestre:

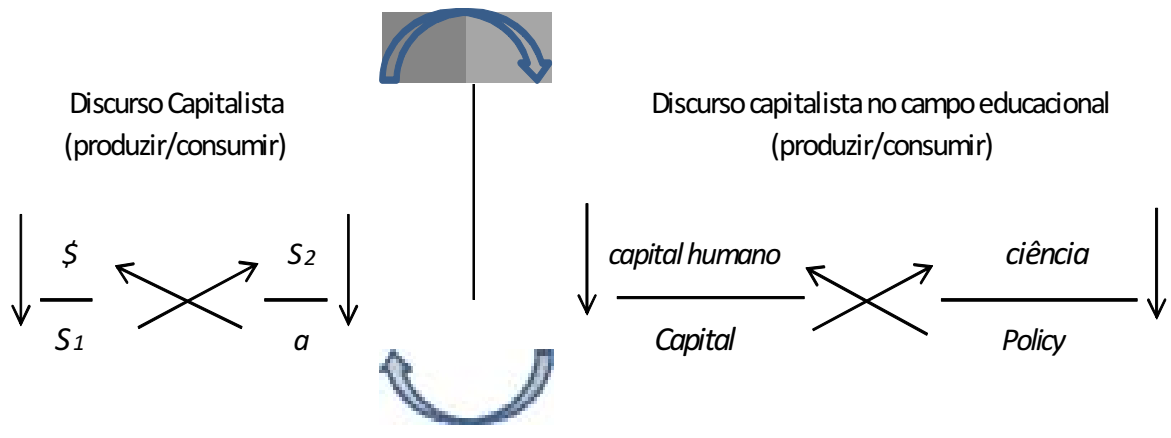

O capital humano ocupa o lugar do sujeito (\$), sustentado pela verdade significante do poder do capital (S1). O sujeito dividido, por sua vez, está determinado pela política educacional como mão de obra qualificada, que compete para a produção do gozo capital. Esse discurso revela que o sujeito, enquanto capital humano em potencial, encontra-se no lugar de dominância como sujeito dividido, ou seja, ele possui a ilusão de que detém o poder de negociar sua posição na divisão social do trabalho em troca de maior poder de consumo. A política educacional segue sob o imperativo da ciência, como perda (objeto a), que é o mais-de-gozar produzido pelo domínio do discurso capitalista no campo educacional. A política educacional, enquanto mais-de-gozar do capitalismo, pode ser lida como investimento para produção de mais capital humano, que, por sua vez, retorna como mais-valia para o capitalista. Nesse caso, o resultado é a produção de aumento do individualismo e da competitividade para o sujeito, que trabalha cada vez mais para produzir os objetos de consumo para seu gozo.

Com a dominância do discurso capitalista no campo da educação, as políticas educacionais, como promessa de geração de mais-valia, formam um indivíduo animado pelo desejo do capitalismo. Esse discurso produz o sujeito consumista, ao mesmo tempo que dirige todos os seus esforços na produção de objetos de desejo, trocando horas de trabalho por uma promessa de gozo. De outro modo, o sujeito do desejo fica foracluído; no lugar da falta, característica 
do desejo, os produtos de consumo vêm ocupar a ilusão de um gozo pleno, absoluto, sem limites, que remete a uma política do gozo. $\mathrm{O}$ aspecto econômico da educação, enquanto formação de "capital humano", passa a ser valorizado e operacionalizado em termos de mercado, em que o conhecimento se transforma em valor, marca recente de nossa "sociedade do conhecimento". Assim, assistimos à migração das técnicas administrativas de mercado para a administração pública, assim como aos critérios de avaliação e aos exigentes padrões de qualidade e competitividade dos serviços privados sendo aplicados no campo das políticas educacionais, por exemplo.

O que este discurso revela é que a política educacional ocupa o lugar da perda, que volta como mais-valia, seguindo a homologia do mais-de-gozar, conforme apontou Lacan (1992), produzindo o sujeito animado pelo discurso capitalista. Como sabemos, tal discurso corresponde ao desmantelamento dos laços sociais, transformando tudo e todos em objetos de produção e consumo. É o que ilustra o cenário macroeconômico atual, no qual acompanhamos a reestruturação internacional do trabalho, que exige profissionais com novas disposições e habilidades, consideradas essenciais para os bons resultados econômicos. Consequentemente, tais transformações refletem sobre os sistemas educacionais do mundo inteiro: a nova pedagogia discursa sobre o desenvolvimento de habilidades e competências desejáveis ao pleno desenvolvimento humano. O saber deixa de ser atribuído à operação de trabalho para ser um saber de capitalista; deixa de ser a lei que regulariza um tipo de laço e passa a ser lei do mercado. O que se produz sob o imperativo desse discurso, a mais-valia, no lugar da perda pulsional, será destituído de seu valor, na medida em que a passagem do discurso do mestre para o discurso do capitalista representou, justamente, a destituição desse saber, operando a foraclusão da lei significante e do sujeito do desejo.

Isso também acontece com o campo da educação sob a inscrição desse discurso - apesar de o Estado manter a ilusão de que está agindo por boas causas, assim como o trabalhador tem a ilusão de que participa do capital como consumidor, é o poder econômico que sustenta as políticas educacionais, que reproduzem, por sua vez, a mais-valia por meio da formação de capital humano, que retorna como taxa de lucro absorvida pelo 
capital. Como vemos, tanto o aluno como o professor, o gestor, o pesquisador, o político, todos equivalem ao proletário para o capital, sendo considerados como valor de troca e de uso, como agentes de uma agência ou operários de uma mesma fábrica.

Como efeito, sob a globalização econômica e financeira do capital, temos um aumento de interesse sobre as políticas educacionais, principalmente para a produção de capital humano cada vez mais qualificado, aumentando as exigências sobre o produto dos sistemas educacionais daí o discurso do fracasso da política educacional quando das impossibilidades de produzir capital humano de excelência. Nesse ponto, encontramos a outra face do discurso do capitalismo no campo educacional, sua produção enquanto discurso universitário-científico, que se associa ao discurso do domínio e do poder

Assim, a ênfase dominante exercida pelo discurso capitalista se desdobra, também, sobre o discurso da universidade, que pode ser lido a partir da posição que a universidade assume frente ao capitalismo. Ao colocar o fracasso da política educacional como sintoma produzido pelo discurso do mestre moderno, buscamos interrogar o lugar e o papel que a universidade ocupa e desempenha na produção desse campo concreto de realidade. Como um discurso recente da civilização, a universidade tem que responder qual é a sua posição frente ao domínio do capitalismo no campo da educação. Essa resposta remete ao discurso que enuncia sua própria verdade: a Universidade está a serviço de quem?

Como último discurso, propus associar o discurso universitário à produção do discurso universitário-científico de análise da política educacional, que, nesta abordagem, está implicado com o discurso do capitalista da educação. Vejamos sua inscrição na estrutura do discurso:

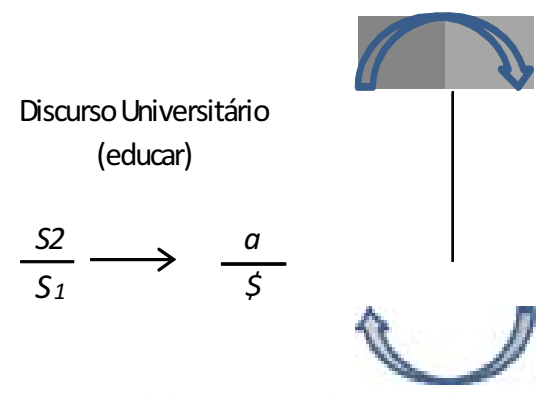
Discurso universitário-científico de análise da política educacional (tudo pelo saber)

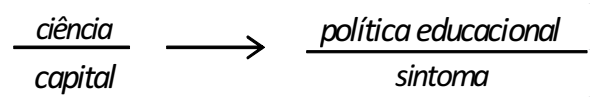


Nesta fórmula, temos o sujeito dividido (\$) como sintoma produzido pelos discursos dos mestres modernos, injunção entre o capital e a ciência, que ocupam o campo do domínio e do sujeito. Nesta posição de agente, a ciência reduz o outro à posição de objeto do conhecimento. Assim, ela age em nome do saber (S2), como um "agente autorizado" à produção de conhecimento sobre a política educacional (acima à direita), essa que surge como objeto $a$, causa do desejo científico. O que esse discurso oculta é o capital enquanto poder que sustenta sua verdade (abaixo à esquerda). Na medida em que tudo que é tratado pelo discurso da universidade é determinado pelo saber, tudo que se encontra no campo do outro significante é objetificado, assim como acontece com o objeto $a$ e o sujeito dividido, resultando, no caso acima, na produção do sujeito sintomatizado, que está dividido justamente naquilo que implica o seu desejo, por um lado, e no sentido que adquire enquanto produto de avaliação ou resultado da policy, por outro, sendo identificado como produto dessa operação discursiva.

Vimos que as práticas das políticas educacionais se desdobram como demandas específicas de conhecimento especializado sobre o real da educação, como as pesquisas que se realizam mediante diagnósticos e análises da política educacional, em que o ciclo da política, ou a implementação e avaliação, surgem como objeto $a$, cau- 
sa do desejo de saber da ciência. Desse modo, o campo produzido pelo discurso científico de análise das políticas educacionais remete ao lugar do agente ocupado pela ciência (S2), ocupando como mestre moderno o mesmo lugar que ocupava o mestre antigo. Como significante-mestre, o saber passa a dominar o campo do objeto, o campo do outro. Quando se trata do campo da ciência, o conhecimento produzido por esse discurso, ao ser universalizado, retorna como poder sobre o outro, assim como de fato ocorre quando a experiência do implementador/educador vai gradativamente sendo substituída em nome de novos conhecimentos, procedimentos, de novas pedagogias etc. - o que se opera é um conhecimento que desapropria o saber do educador, negando-o como sujeito. De modo semelhante, o aluno também fica eclipsado a partir da posição sintomática que ocupa na estrutura, na medida em que o discurso da análise de políticas educacionais o retrata como objeto, sobrando-lhe a identificação com esse lugar como produto ou resultado da policy.

Sabemos que, na lógica dos discursos do domínio, o sujeito sofre um apagamento, referente à foraclusão do simbólico enquanto dimensão subjetiva, produzido pela própria escritura do discurso. Ao produzir seu próprio objeto de saber, a ciência apaga o sujeito. Será justamente o simbólico foracluído pelo discurso universitário-científico que retorna no real como fracasso do simbólico. Para esse sujeito, resta-lhe a desistência, a revolta ou o sintoma. Ao desistir do ideário da educação, o sujeito fica fora do discurso, como os loucos, os evadidos, os desistentes, os excluídos etc. Ao se revoltar contra o discurso oficial, o sujeito tenta retomar as rédeas do poder. Aqui, vemos o inconsciente como política do desejo que instaura em ato um novo estado. Como exemplo, há os estudantes universitários que se revoltam contra o discurso hegemônico do mestre moderno, reivindicando reconhecimento do Estado, em sua posição de poder, enquanto escravos do saber. Ao sintomatizar, temos o sujeito do laço social instaurado pelos discursos modernos; enfim, o discurso concreto que instaura o campo da realidade transindividual do sujeito e se manifesta como produto dos discursos educacionais.

Até o momento, vimos que ao sujeito situado como dejeto sob o saber-fazer do Outro resta a imputação do fracasso, esse que será lido de acordo com a convenção dos resultados (metas, escalas de proficiência etc.). Vimos, também, como a produção do discurso do capitalismo no campo educacional, em que o saber especializa- 
do se situa como a outra face do problema, como produção de conhecimento e informações qualificadas sobre a implementação de políticas educacionais, responde tanto às aspirações sociais da policy quanto às exigências da economia competitiva globalizada, em que a competitividade e o crescimento das exigências são consequências do poder do capital, cuja demanda por capital humano "qualificado" torna-se cada vez maior.

A dominância administrativa desse discurso da sociedade contemporânea recai sobre as políticas educacionais, envolvendo tanto os implementadores, como objeto das ações educativas, que são cobrados por melhores resultados, quanto os alunos, que ocupam a posição de suporte do gozo do mestre capitalista. Este torna-se um imperativo no campo discursivo que determina a educação, como meio de acesso ao gozo do mercado, por meio das características competitivas da vida capitalista e do aumento das exigências sobre o desempenho dos sujeitos. De outro modo, compreendemos esse imperativo moderno das sociedades como promessa de satisfação e progresso que esgota tudo e todos que encontra pela frente: estude mais, trabalhe melhor, goze de novo!

\section{Considerações finais}

Conforme o exposto, vimos que o discurso universitário responde, em grande parte, por essa função de produzir um conhecimento que é demandado pela gestão das políticas educacionais, pelos políticos, pelos especialistas, pela economia globalizada, justamente na medida em que destitui os implementadores de seu saber-fazer e reduz o aluno ao resultado da política educacional. Como efeito desse discurso, o sujeito fica totalmente tributário do Outro que o determina, que, no nosso caso, retrata a lógica da uniformização dos alunos por meio dos resultados aferidos no que concerne à análise dos sistemas educacionais. É importante lembrar que se trata da diferença singular do desejo e não da desigualdade individual e social que, como sabemos, também se reproduz por meio dos processos de educação.

De outra forma, segue nossa premissa de que o enunciado fracasso educacional retrata a emergência do sujeito na estrutura e equivale ao retorno, no real, da subjetividade foracluída pelos discursos 
dos mestres modernos. O sujeito passa a ser identificado com o resultado e rotulado e reconhecido de acordo com os padrões normativos. Temos, assim, toda a extensão da noção de acontecimento do sujeito, como uma ordem simbólica que é negada no discurso da ciência, retornando como o real não simbolizado. O sujeito como fracasso é, justamente, a ordem simbólica (sujeito) que retorna como furo no real. Em suma, o fracasso é o acontecimento do sujeito na estrutura.

Se, por definição, o real é o simbólico fracassado, exatamente por ser impossível ordenar o real, então, o fracasso é inerente ao real da política. Essa impossibilidade remete ao conflito pulsional como elemento constitutivo das práticas sociais. Como dimensão simbólica, o discurso da política educacional abre a possibilidade de realização do desejo à custa de lidarmos com a impossibilidade de toda satisfação, como articulação entre a lei e o desejo.

É por ser um sintoma do que falha que o fracasso aponta para o sujeito do desejo, já que, como a psicanálise ensina, onde está o sintoma, está o sujeito. A ênfase na dimensão dos estudos da policy recobre justamente tais práticas, procedimentos e conhecimentos técnico-científicos de racionalização e controle burocrático que acabam suturando o sujeito, sobrepondo-se a todo conflito pulsional que permeia os laços sociais do campo educacional.
Como sabemos, a inferência psicanalítica recobre a dimensão singular do humano, que não se acomoda em nenhuma noção universal, tal como a que se objetiva enquanto ideais, seja de uma política, seja de um ideal pedagógico e/ou educacional. A tendência racional e universal da policy regida por sua própria "razão instrumental" de domínio e controle está limitada por seu avesso, o desejo, que separa e singulariza o sujeito no particular, ou seja, no ato da implementação, apontando para uma impossibilidade irredutível.

Entretanto, dizer que é impossível não significa que não há nada a se fazer, no sentido de um niilismo reativo ou passivo, mas aponta para uma leitura possível sobre a realidade das políticas educacionais, que, como propomos, deve considerar a presença do sujeito nas etapas da política como um acontecimento significante. Fundamentalmente, o impossível como conflito implicou pensar o possível como conflito que não é solucionado. Entretanto, em grande medida, o discurso científico e universitário sobre a implementação de políticas educacionais ocupa-se da produção contínua de sentidos, visando a "solucionar" os conflitos existentes daquilo que se denominou de fracasso de uma dada prática, política ou programa educacional. Trata-se, precisamente, da elisão do sujeito produzida por meio desses discursos. Tal dimensão implica duas questões: a de que o fracasso está como uma condição es- 
trutural para qualquer estratégia (planejamento) de implementação política, como impossível, e a do o impossível de a produção simbólica controlar esse real, que sempre se inscreve como inominável, como falta, ou, na lógica do discurso do controle, como fracasso, que está sempre aquém das expectativas. Em síntese, ao operar um deslocamento do campo de implementação de políticas educacionais para a leitura psicanalítica da linguagem e da comunicação, a política educacional pôde ser inscrita como enunciado que ordena os laços sociais; entretanto, ela necessita de pessoas que sustentem seu discurso, sendo que o efeito produzido, enquanto significação, está determinado pela posição que ocupa o sujeito da enunciação, que, devido à própria divisão constitutiva, torna impossível qualquer identidade entre significado e significante, entre o simbólico e o real da implementação - mesmo que existam boas intenções, recursos financeiros e humanos, a execução de uma política sempre apresentará hiatos entre o que é formulado e o que é implementado.

Ao colocar a política educacional como uma prática impossível, fadada ao fracasso, não quero destituíla de seus anseios legítimos de socialização, humanização, formação e subjetivação que demanda a sociedade de seres falantes. É importante frisar: essa impossibilidade ou fracasso não significa apontar-lhe a impotência, não significa que ela é total- 
mente irrealizável. Ao contrário, e de modo paradoxal, o impossível indica justamente o que é possível, ou as possibilidades dessas práticas sociais como um saber que faz do impossível o possível, em que a educação pode ser mantida no horizonte ético dessas práticas. O fracasso da política educacional adquire novo sentido como fracasso e acontecimento do sujeito, o qual podemos pensar no discurso concreto, que retrata o sujeito dividido, enquanto presença de laço social. $\mathrm{O}$ fracasso como sintoma passa a ser interpretado na sua função constitutiva, na medida em que se torna ao mesmo tempo condição do social e o modo particular de inscrição do sujeito no discurso, ou seja, no laço social.

Nessa perspectiva, o fracasso pode ser pensado como possibilidade de uma prática que inclua a subjetividade, o outro, a diferença, o acontecimento, como aponta a existência desse sujeito inscrito por meio do laço social da política educacional. Esse fracasso torna-se sintomático para o sujeito na medida em que este é reduzido aos discursos do domínio, da padronização e controle, com o objetivo de alcançar um ponto preciso de desempenho, que, como tentativa de acerto, falha no intento. Reconhecer que o fracasso é o acontecimento do sujeito, na política educacional, implica a aposta contínua em novas formas de gestão, mais criativas e menos tecnocráticas, reorientando a análise e fortalecendo os canais de responsabilização do sujeito com sua palavra, com sua existência e sua vida, num sentido ético do desejo, portanto, na perspectiva do não todo. Como avesso do significante fracasso, a possibilidade de incluir o sujeito do desejo implica, ao menos, um discurso que possibilite um laço social possível por meio da política educacional, questionando, no campo social, os discursos da era tecnocientífica e do capitalismo moderno de uniformização do rendimento acadêmico de sucesso, os quais transformam tudo e todos em produto, objeto, meio de gozo e mais-valia. Nesse sentido, o discurso psicanalítico pode produzir um discurso que sirva de entrave à dominância dos discursos dos mestres modernos no campo e na abordagem da implementação das políticas educacionais, ressignificando o fracasso educacional que se reproduz por meio da lógica da exclusão. 

JECT EMERGENCY

\section{Abstract}

This article aims to interrogate the discourse about the "failure of educational policies" as a symptom, associated with the several types of discourse: the master's, the capitalism's, and the university's. All of them imply the actual presence of the unconscious in the social links established by educational policies nowadays. In addressing the educational failure as a symptom, we shift from the usual question "W by do educational policies fail?" to argue in favour of the bypothesis that failure itself mirrors the subject event in the discoursive structure. Our analysis showed the importance of including the subject of desire in the field of educational policies analysis.

Index terms: educational failure; educational policy; psychoanalysis; discourse theory.

EL FRACASO EN LA APLICACIÓN DE LAS POLÍTICAS EDUCATIVAS: SÍNTOMA Y EMERGENCIA DEL SUJETO

\section{Resumen}

Este artículo pretende interrogar el discurso sobre el "fracaso de la política educativa" como un sintoma asociado con el discurso del maestro, del capitalismo y de la universidad, lo que implica la presencia real del inconsciente en los lazos sociales establecidos a través del campo de las políticas educativas en la actualidad. Tratar el fracaso educativo como sintoma resultó en un cambio de la pregunta habitual "¿Por qué las políticas educativas fracasan?", para apoyar la hipótesis de que el fracaso retrata el acontecimiento del sujeto en la estructura discursiva. El análisis demostró la importancia de incluir el sujeto del deseo en el campo del análisis de las políticas educativas.

Palabras clave: fracaso educativo; política educativa; psicoanálisis; teoría del discurso. 


\section{REFERENNCIAS}

Arendt, H. (1992). Crise na educação. In H. Arendt, Entre o passado e o futuro (M. W. B. de Almeida, Trad., pp. 221-247). São Paulo: Perspectiva.

Figueiredo, A. C. \& Figueiredo, M. (1986, setembro/dezembro). Avaliação política e avaliação de políticas: um quadro de referência teórica. Análise \& Conjuntura, 1(3), 107-127.

Lacan, J. (1992). O Seminário, livro 17: o avesso da psicanálise (A. Roitman, Trad.). Rio de Janeiro: Jorge Zahar.

Passone, E. F. K. (2012). Fracasso na implementação de políticas educacionais: uma abordagem pelo discurso psicanalítico. Tese de Doutorado, Faculdade de Educação, Universidade Estadual de Campinas, Campinas, SP.

Preal (Programa de Promoção da Reforma Educativa na América Latina e Caribe) (2001). Ficando para trás: um boletim da educação na América Latina. Brasil: Preal.

Senne, F. (2009). Educação e mídia: a cobertura jornalística em foco. Recuperado em 24 de junho, 2011, de Com ciência (Revista Eletrônica de Jornalismo Científico): http://www.comciencia.br

eric@nepp.unicamp.br ericpassone@yahoo.com.br

Rua Papa Leão XIII, 10 casa 3 13082-793 - Campinas - SP - Brasil. 